\title{
Memoria y disidencias gráficas: narraciones de una historia con las $\operatorname{artes}^{1}$
}

\author{
Memory and graphic dissidences: narrations of a history with arts
}

\author{
Laura Paola Fajardo Leal \\ Universidad Distrital Francisco José de Caldas \\ arualeal1800@gmail.com
}

Fecha de recepción: 12 de agosto de 2019

Fecha de aprobación: 21 de diciembre de 2019

\section{Resumen}

En contraste a la noción tradicional de Historia anclada al pensamiento cronológico y los cánones estilísticos del arte, surgen una suerte de microrrelatos visuales que, distantes de las simples metáforas asumidas en la creación gráfica, admiten una lectura entre líneas de la Historia como escenario para dinamizar la memoria y las prácticas artísticas.

Es así como estos microrrelatos visuales entran en diálogo con las concepciones del pasado y sus incidencias en el presente para irrumpir en aquellos discursos hegemónicos replicados desde la Historia en su perspectiva monumental y anticuaria.

Palabras clave: Historia, gráfica, prácticas artísticas, memoria.

\begin{abstract}
In contrast to the traditional notion of History anchored to chronological thinking and the stylistic canons of art, some kind of visual micro-stories arise which, distant from the simple metaphors assumed in graphic creation, allow a subtextual reading of History as a scenario to dynamize memory and artistic practices.

Thus, these visual micro-stories dialogue with the conceptions of past and their incidents in the present in order to break into those hegemonic discourses replicated from History in their monumental and antiquarian perspective.
\end{abstract}

Keywords: History, graphics, artistic practices, memory.

$1 \quad$ Artículo derivado de proyecto de investigación - creación en curso actualmente titulado: "Entre cemento y adhesivo: construcciones de sentido de espacio público en Bogotá a partir de la práctica del sticker urbano" autoría de Laura Paola Fajardo Leal, Maestría en Estudios Artísticos - Universidad Distrital Francisco José de Caldas. 


\title{
Introducción
}

\begin{abstract}
“... Necesitamos la Historia, pero la necesitamos de forma distinta de como la necesita el hombre mimado que deambula ociosamente en el jardín del saber, por más que este contemple con altivo desdén nuestras necesidades y penurias, tan rudas y purgadas de gracia”.

Friedrich Nietzsche - Segunda consideración intempestiva. Sobre la utilidad y los inconvenientes de la historia para la vida (fragmento).
\end{abstract}

De acuerdo con la perspectiva convencional de la Historia, quien se acerca a ella lo hace desde la más pura imparcialidad. Es desde allí donde habitualmente distinguimos y comunicamos un paradigma histórico anclado a una temporalidad que adquiere una suerte de vigor desde el reconocimiento. Así pues, nos situamos bajo un lugar de enunciación próximo a la retención de los sucesos donde no quisiéramos perder ni una sola de las imágenes que componen lo que creemos que es nuestro pasado como humanidad.

De esta forma, conferimos a la Historia una tendencia canónica que recae en la legitimación de unos relatos específicos y en la evasión de otros, no solo por su desconocimiento sino porque manifiestan todo tipo de rupturas y dicotomías que cuestionan la absoluta "objetividad" y que hacen posibles formas de reescritura ya no solo de lo que fue sino de aquello que sucede en el aquí y el ahora.

En este sentido, el plano de las artes no es ajeno a la dinamización de la Historia. De la mano de la Historia imparcial, surge una Historia del arte que establece nexos con hitos espaciotemporales con una cierta "deuda" hacia epistemologías «otras» que pluralizan esta Historia irrumpiendo con su horizontalidad que, en palabras de Benjamin, "suministra la masa de hechos que se necesita para llenar el tiempo homogéneo y vacío"2.

Así las cosas, en el presente artículo propongo un acercamiento a una Historia con las artes que convoca a una diversificación de las prácticas artísticas como construcción de formas discontinuas de comprender y resignificar la Historia desde las divergencias, las intersensibilidades y las subjetividades. Para ello, convoco a un abordaje de lo que he denominado como "disidencias gráficas"; manifestaciones visuales que trascienden las dinámicas de cooptación institucional y que plantean una mirada política desde la resistencia -como sucede con Puro Veneno- y desde las formas de pensar la Historia y los microrrelatos junto a las memorias de ciudad. Sea este último mi caso particular a través del sticker urbano.

En consecuencia, asumo las producciones visuales como instancias de creación e interpelación de la Historia, pero a su vez, como mecanismos de intervención de

2 Walter Benjamin, Tesis sobre la historia y otros fragmentos. (Bogotá: Ediciones Desde Abajo, 2010), 30. 
la misma a través de la memoria personal; pues como menciona Burke: "de acuerdo con el paradigma tradicional, la historia es objetiva... En la actualidad este ideal se considera, en general, quimérico... no podemos evitar mirar al pasado desde una perspectiva particular"'

\section{Tradicionalismo histórico en las artes}

"Solo en tanto se produce aquella nube que todo lo encierra, un destello luminoso; es decir, solo en tanto posee el poder de utilizar el pasado para la vida y de transformar lo acaecido en Historia, el hombre se vuelve humano".

Friedrich Nietzsche - Segunda consideración intempestiva. Sobre la utilidad y los inconvenientes de la historia para la vida (fragmento).

Pensar en función de la Historia nos remite, quizá de manera automática, a la imagen de lo que fue y, en efecto, a los discursos que han legitimado dicha idea del pasado. De acuerdo con Benjamin: "el pasado solo es atrapable como la imagen que refulge para nunca más volver en el instante en que se vuelve reconocible"4; de allí que, remitirse a la noción tradicional de Historia, apele directamente a la necesidad de capturar de modo fidedigno las márgenes del tiempo pretérito que los contextos hegemónicos han destacado.

No obstante, frente a estos bordes que delimitan el continuum de la Historia convencional y cristalizan narrativas plurales, sobresale la Historia de los vencedores, opresores y personajes ilustres que actúa como panacea de los libros de texto y de la progresión de una Historia del arte como una línea horizontal que pretende abarcar los hitos de producción intelectual en forma de estilos y transiciones propios de una trastocada estética.

Al respecto, Nietzsche plantea la existencia de una Historia monumental en la cual perdura la grandeza de las hazañas. Esta perspectiva, fundamenta la credibilidad en los cánones estilísticos como estandartes de la producción artística y, en consecuencia, de la mirada primordialmente eurocéntrica que ha adquirido paulatinamente la Historia del arte universal.

Así las cosas, en la Historia monumental: “... vivirá el monograma de su ser intrínseco, una obra, una hazaña, una iluminación extraordinaria o una creación; vivirá porque el mundo posterior no podrá prescindir de él"s. De forma que, las aproximaciones a la Historia se convierten en un hacer catedrático donde la "obra de arte"

3 Peter Burke, "Obertura: la nueva historia, su pasado y su futuro" en: Formas de hacer historia, ed., Peter Burke [et al.] (Madrid: Alianza editorial, 2003), 19.

$4 \quad$ Walter Benjamin, Tesis sobre la historia y otros fragmentos. (Bogotá: Ediciones Desde Abajo, 2010), 21.

$5 \quad$ Friedrich Nietzsche, Segunda consideración intempestiva. Sobre la utilidad y los inconvenientes de la historia para la vida. (Buenos Aires: Libros del Zorzal, 2006), 32. 
conquista su valor cultual ${ }^{6}$ y se inserta en el plano de la cultura como un "artefacto creativo" digno de ser aceptado y admirado sin que ello quebrante en su sentido radical su poder aurático ${ }^{7}$.

Ante este panorama, esta Historia de cronologías, progresos y representaciones artísticas de manos ilustres, "atenúa la heterogeneidad de los motivos y móviles para presentar, a costa de la causa, como ejemplar de ser imitado, su effectus monumental"8. Por tal razón, la Historia monumental se torna reiterativa en el plano de las artes dada la continuidad e incluso predicción de aquello que genera resonancia en los contextos de recepción.

A esta conciencia histórica como continuidad que trae a cuestas las magnitudes del pasado en su faceta más plástica ${ }^{9}$, se suma la Historia de las recuperaciones y de "momificación" de las experiencias humanas que Nietzsche denomina Historia anticuaria. Esta última que, en el plano de las artes, refiere a las prácticas de retención del pasado que amenaza por desaparecer.

En este orden de ideas, proliferan las preocupaciones por la salvaguarda del patrimonio a través de las estrategias de conservación y de restauración en su circunstancia más extrema. La Historia anticuaria "pertenece además a quien conserva y venera, a quien contempla con fidelidad y amor el lugar del que viene y por el que es lo que es" $"$. De allí que sólo es admisible para la Historia aquello que es digno de almacenarse para ser contemplado en su carácter sobrehumano.

En efecto, la Historia del arte se convierte en sinónimo de pervivencia del genio creador que pone a merced de la mirada y el gusto un objeto en una vitrina a la cual es posible acercarse de manera limitada debido al status que ha adquirido en la cumbre de lo sublime; un posicionamiento que se reafirma a través de las secuencias narrativas que construyen el hilo del tiempo ${ }^{11}$

6 Me refiero al carácter retórico y movilizador de afectos y artilugios discursivos propios de la representación artística.

7 En este aspecto, resulta pertinente retomar los planteamientos de Benjamin (2003) en función del aura de la obra de arte cuando depende del entretejido del espacio y tiempo de su creación. Siguiendo al autor, la decadencia de este poder aurático está determinada por el surgimiento de masas y la intensidad de sus movimientos, algo que pareciera paradójico para la afirmación en referencia. Sin embargo, propongo una perspectiva del aura vinculada, en suma, a su "autoridad totémica"; es decir que, el peso histórico que adquieren ciertas "obras de arte" desde la perspectiva monumental, refuerza su relevancia en un contexto determinado.

$8 \quad$ Friedrich Nietzsche, Segunda consideración intempestiva. Sobre la utilidad y los inconvenientes de la historia para la vida. (Buenos Aires: Libros del Zorzal, 2006), 35.

9 Es decir, en su componente más maleable. La Historia alimenta la resignificación del pasado; de manera que, este último asume una apariencia plenamente dúctil.

10 Friedrich Nietzsche, Segunda consideración intempestiva. Sobre la utilidad y los inconvenientes de la historia para la vida. (Buenos Aires: Libros del Zorzal, 2006), 40.

11 No sobra destacar los lugares de enunciación desde los cuales se piensan inicialmente los museos nacionales como escenarios de divulgación del patrimonio $\mathrm{y}$, en efecto, de un relato homogéneo de nación donde parecen fusionarse las dos instancias históricas: monumental y anticuaria. En este orden de ideas, los museos nacionales surgen en primera medida, bajo el propósito de salvaguardar el acervo cultural que se integra 
En síntesis, la Historia anticuaria se fundamenta en la bipolaridad del valor de la obra de arte en términos de lo que llamaría Benjamin como ritual y de exhibición. Así pues:

El valor ritual prácticamente exige que la obra de arte sea mantenida en lo oculto: ciertas estatuas de dioses solo son accesibles para los sacerdotes en la cella; ciertas imágenes de la virgen permanecen ocultas por un velo durante gran parte del año; ciertas esculturas de las catedrales góticas no son visibles para el espectador a nivel del suelo. Con la emancipación que saca a los diferentes procedimientos del arte fuera del seno del ritual, aumentan para sus productos las oportunidades de ser exhibidos ${ }^{12}$.

Por lo tanto, una Historia del arte pensada desde el hacer aditivo es enteramente redundante en la medida que, con los hechos o representaciones dignas de pertenecer a la Historia, se logra perpetuar el efecto monumental y reduccionista. De este modo, aquello que fue meritorio en el pasado, será susceptible de ser relevado por otra creación en el presente, pero no con el mismo armazón retórico. Además, pareciese inverosímil fraccionar el funcionamiento mecánico de la Historia convencional. Al respecto, son sugerentes las palabras de Nietzsche cuando menciona que: "el historicismo se contenta con establecer un nexo causal entre distintos momentos de la historia. Pero ningún hecho es ya un hecho histórico solamente por ser una causa"13

\section{Historia y juicio: Hacia una historia crítica desde las visualidades}

“... Te han llenado la boca de paja, Simón, te han vuelto estatua, medalla, estampilla y hasta billete de banco. Porque no todos los ríos van a dar a la mar, algunos terminan en las academias, en los pergaminos, en los marcos dorados: lo que también es el morir. Pero y si de pronto, y si quizás, y si a lo mejor, y si acaso, y si tal vez algún día te sacudes la lluvia, los laureles y tanto polvo, quién quita”.

María Mercedes Carranza - De Boyacá en los campos (fragmento).

Ante los estadios inconclusos de la Historia monumental y crítica, surge una suerte de deuda con el pasado reciente que activa las búsquedas por aquello que acontece y que ha sido silenciado o negado en la construcción espacio temporal de la Historia tradicional. Por consiguiente, surgen instancias de aproximación a una Historia crítica que "desentierran las raíces con un cuchillo y desdeñan cruelmente las tradiciones". ${ }^{14}$

a sus diferentes colecciones. Estas últimas pensadas como la materialización de dicho relato.

12 Walter Benjamin, La obra de arte en la época de su reproductibilidad técnica. (México: Editorial Ítaca, 2003), 53.

13 Friedrich Nietzsche, Segunda consideración intempestiva. Sobre la utilidad y los inconvenientes de la historia para la vida. (Buenos Aires: Libros del Zorzal, 2006), 32.

14 Ibid., 48. 
Así pues, las posibilidades de la historia crítica revelan la intensidad de un análisis hacia y con aquello que presumimos convencionalmente como "periférico", lo cual sitúa en tensión los parámetros de imparcialidad con los cuales se construye la Historia y las cercanías a esta desde las subjetividades. Ello, sin lugar a dudas, alimenta la resignificación de la Historia a contrapelo que ingresa al plano del aquí y el ahora en forma de intervención directa.

Bajo estas concepciones, surge la Historia desde abajo que como menciona Sharpe: "abre al entendimiento histórico la posibilidad de una síntesis más rica, de una fusión de la historia de la experiencia cotidiana del pueblo, con los temas de los tipos de historia más tradicionales"15; ello indica que, aunque la Historia desde abajo no desatienda del todo al "arriba", no es de exclusiva dependencia del historiador o, para el caso particular, del productor artístico.

La Historia desde abajo asume el enorme desafío de superar el profesional que enjuicia y profundizar en algo más que la reivindicación de las memorias olvidadas; la Historia crítica escudriña en las intersensibilidades en tránsito y, en efecto, trastoca de manera permanente todas aquellas narrativas que fundamentan el campo personal de los sujetos.

Partiendo de estas consideraciones, en el apartado siguiente, profundizaré en una alternativa a la Historia crítica con las artes pensada desde aquello que he denominado "disidencias gráficas", refiriéndome a una superación de las metáforas y simbolismos reforzados desde la Historia convencional que parecen replicar un hacer enteramente conceptual y rígido que instrumentaliza tanto las narrativas emergentes desde las subjetividades como su fuerza enunciativa en términos de la acción política.

\section{Revisiones a una Historia con las artes desde la disidencia gráfica}

"Los rifles silban desafinados, la canción de muerte que han creado. Los de derechas se tropiezan con los de izquierdas y viceversa. Estamos insultando a la ley y estamos en su truco al dinero como perdedores, como perdedores, como perdedores, estamos en su juego".

Eskorbuto - Nadie es inocente (fragmento)

El espacio público se ha convertido en el escenario de la agitación gráfica y, en consecuencia, de múltiples lecturas respecto a las disidencias de carácter político que dialogan en contraste $o$ distanciamiento radical frente a la Historia legitimada en el marco del proyecto de nación. Según Roca y Suárez, durante la última década del siglo XX e inicios del siglo XXI, la producción cultural sostuvo diálogos más fervientes con la historia contemporánea, toda vez que las obras

15 Jim Sharpe, "Capítulo 2: historia desde abajo" en: Formas de hacer historia, ed., Peter Burke [et al.] (Madrid: Alianza editorial, 2003), 51. 
"Fueron sintomáticas de la encrucijada crítica que caracterizó las prácticas del arte contemporáneo a nivel mundial, la cual establecía vínculos críticos con la cultura de masas y con los medios de comunicación masivos, con las tensiones entre los imaginarios de la alta cultura y de la cultura popular, y con la propia institucionalidad del arte y sus relatos" 16 .

Estas proposiciones caracterizaron un punto de partida para pensar las contrahistorias que cuestionaron las prácticas conservadoras de las instituciones artísticas; de allí que la emergencia de nuevas narrativas en el panorama de las artes plásticas y visuales en Colombia asistiesen al "resquebrajamiento de los discursos hegemónicos en favor de una pluralidad de tendencias que coexistieron sin la pretensión de imponerse sobre las demás"17

Bajo estas premisas surge Puro Veneno, que más que una iniciativa de resistencia a través de la movilización de distintos formatos gráficos en la ciudad se constituye en un mecanismo de intervención en las calles que, desde el recurso visual, actúa en función de la Historia tomándola como "materia prima”. En palabras de Quintero:

"Un proyecto realizado con coherencia que sale a las calles con carteles, calcomanías y pinturas, armas de resistencia pacífica para no callar. Con dignidad y respeto por la memoria, se proponen a través de la gráfica, imagen y el texto hacer una crítica social para no olvidar. Su insistencia está llena de responsabilidad para informar, denunciar y convoca a un movimiento subrepticio en contra de la corrupción y la violencia" 18 .

De forma que, una exploración hacia la Historia de los vencedores tanto como desde los reservorios ilustres desde la óptica de la contracultura y la Historia crítica, constituye la sustancia de Puro Veneno quienes acusan tener el "antídoto" contra las manifestaciones de barbarie que resurgen en el panorama nacional y se legitiman a través de la unicidad de su Historia:

"El corazón caliente e incendiario combate la sangre fría y sedentaria; las calles como elemento de agitación política sellan otro milenio. Somos el rumor que se con-

16 Silvia Suárez y José Roca, Transpolítico. Arte en Colombia 1992 - 2012. (Bogotá: Lunwerg Editores, 2012), 11.

17 Ibid., 13. A razón de lo anterior, son relevantes los apuntes de Roca y Suárez (2012) respecto a aquello que han denominado como "poética pública" relacionada a las prácticas artísticas que pretenden interpelar al habitante de ciudad a partir de la acción gráfica. El trabajo de Adolfo Bernal que, a través del uso de carteles en la ciudad de Medellín, posibilita el diálogo con los transeúntes cuestionando la publicidad como estrategia de comunicación.

18 Juan Quintero, “¿Qué tan fuerte hay que gritar?” en: Puro Veneno. Antología de una revuelta gráfica. (Bogotá: La Valija de Fuego, 2019), 43. 
vierte en información, compartir y difundir es la consigna. Seguimos haciendo ruido desde el anonimato para proteger y motivar a cualquiera que pueda adherirse a nuestro propósito de ser una parte del antídoto contra las violencias que se viven en nuestro territorio"19

Así las cosas, Puro Veneno, como plataforma masiva de comunicación disidente, descubre el velo del relato nacional unificado en la Historia tradicional a través de las prácticas de divulgación de contenido como un mecanismo de reescritura de la misma y de la persistencia del "no olvidar"; aquello que constituye el punto de partida de este último apartado sobre el papel de la memoria en el ejercicio histórico con las artes que presentaré a continuación.

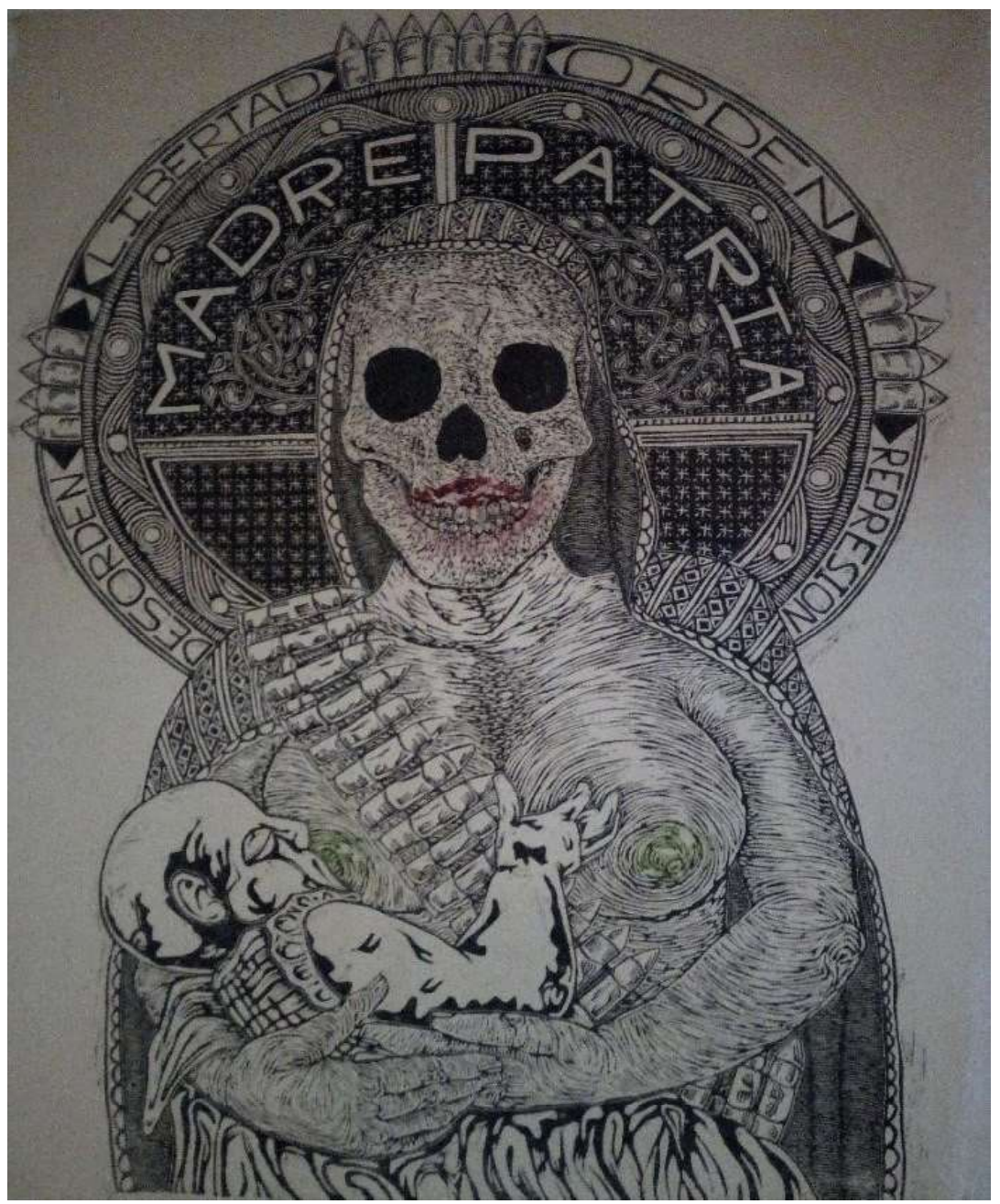

Imagen No 1. Puro Veneno (2018). Madre patria. Exposición de ilustración "el antídoto es el arte". Fotografía propia. 


\section{Dialogos con lo personal: El Bombing como práctica de memoria y reescritura de la Historia}

"Más que hablar de una lectura de la ciudad, habría que hablar por el contrario de una lectura-escritura de la misma, al fin y al cabo las ciudades se inscriben como escrituras estéticas: como tejido de relaciones - afectivas, perceptivas, figurativas, simbólicas-, sobre ellas se traman miles de caminos y de rutas, multiplicidad de prácticas que la sostienen y le permiten su supervivencia, infinidad de puntos de cruce y amalgamas de interferencias que le dan su tono particular y su peculiaridad histórica"

José Montoya - Capítulo 1: entre huellas e íconos. Los palimpsestos estéticos citadinos. (Fragmento)

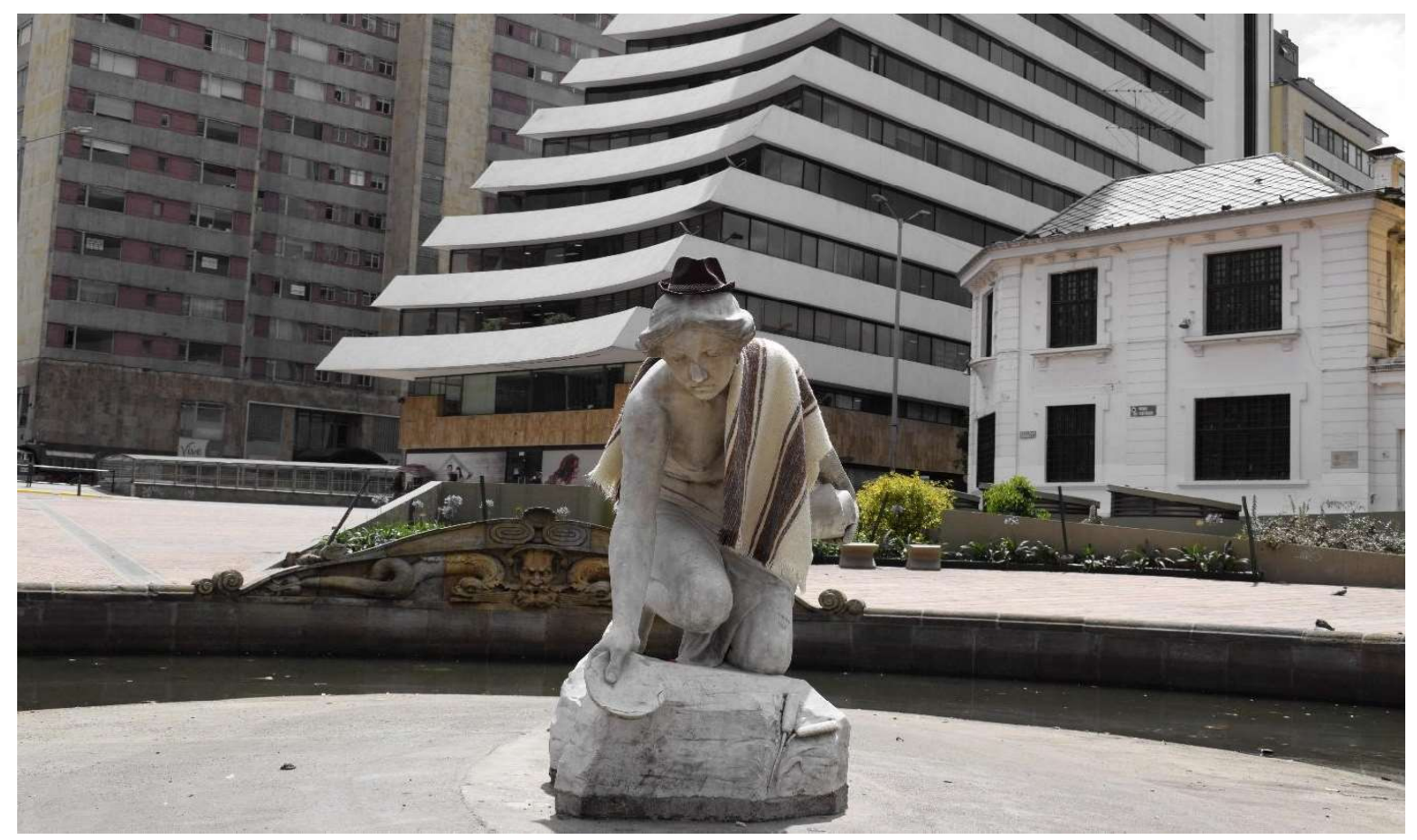

Imagen No 2. Rebeca santandereana. Memorias de ciudad: entre la visualidad y lo personal. Fotografía propia.

Una Bogotá completamente extenuada me resuena en la memoria. Una memoria que la entiende como una ciudad fatigada por el caos, una "memoria que no se construye en abstracto, sino en una serie de acciones y relaciones humanas enmarcadas en un contexto, destinadas a otorgarle un sentido al pasado, presente y futuro" 20 .

20 Alejandra Gaviria, Las calles también hablan. Memoria y espacio público. (Bogotá: Centro de Memoria, Paz y Reconciliación, 2015), 23. 
Una memoria que, como habitante de esta ciudad de nadie he intentado armar, tejer y componer y que pretendo visibilizar a través de lo que empezó como una apuesta fotográfica y terminó convirtiéndose en la materialización de mis posibilidades de resemantización de la Historia a través de las pegatinas dispuestas en las calles y en mi rol como destinataria de esos ecos efímeros que he logrado capturar desde las luchas semánticas y neobarrocas de "otros" en el espacio habitado.

En efecto, convoco con este cierre "visualmente poético" — si se quiere-, a abordar la Historia con las artes a través de la memoria personal que, en palabras Jelin, "involucra referirse a recuerdos y olvidos, narrativas y actos, silencios y gestos" ${ }^{21}$. Así es como surge Rebeca Santandereana, una intervención que se realizó a comienzos del presente año a la conocida escultura situada en el barrio San Diego en Bogotá entre las carreras 12 y 13 con calle 25, y elaborada a mediados de 1926 por la marmolería italiana Tito Ricci.

Esta intervención sucede como una puesta en diálogo entre la Historia ignota de la ciudad, mis evocaciones y olvidos en función de los espacios bogotanos y los puentes que conectan dos instancias de memoria (colectiva e individual) ${ }^{22}$ que, para el caso particular, reafirman las búsquedas diversas y subjetivas de pensar una Historia vinculada con las artes sin prescindir de estas últimas como "herramientas estéticas" para acceder a la Historia, sino para narrarla desde allí, lo que admite una lectura permanentemente polisémica.

Este proceso de creación que actualmente circula por algunos espacios de la ciudad de Bogotá a través del bombing ${ }^{23}$, que asumo de modo personal como territorios, también resuena - a mi entender - tanto con la historicidad del objeto escultórico en el espejo de agua del sector, su presencia tangible y su "invisibilidad a través de la visualidad" como con aquellos tránsitos, aprendizajes y diálogos de la mano de mi abuelo materno que, a saber, se integran paulatinamente a mi memoria personal por ser estos quienes me permiten desde la infancia construir una nueva arista de la historia de la ciudad que me habita y desde la cual me permito narrar tanto las luchas de la ruralidad con relación a lo urbano e incluso, el carácter simbólico de los objetos tradicionales que se mantienen en el imaginario de los habitantes de la ciudad cuando se dialoga respecto a lo distante, periférico, barrial, rural, territorial $-\mathrm{y}$ por qué no mencionarlo-, identitario.

21 Elizabeth Jelin, “iDe qué hablamos cuando hablamos de memorias?” en: Los trabajos de la memoria, Elizabeth Jelin (2001), 1, https://laasociacion.files.wordpress.com/2015/11/memoria-jelc3adn-1.pdf (Consultado el día 8 de agosto de 2019).

$22 \mathrm{Al}$ respecto, es menester señalar la postura de Halbwachs (como se citó en Erll, 2012) respecto a los vínculos de reciprocidad que establecen estas dos instancias de memoria, pues "el individuo recuerda en la medida en que asume la perspectiva del grupo, y la memoria del grupo se hace real y se manifiesta en las memorias individuales" (p. 21).

23 Intervención directa a los espacios, cubrir un área específica con formatos visuales diversos. 


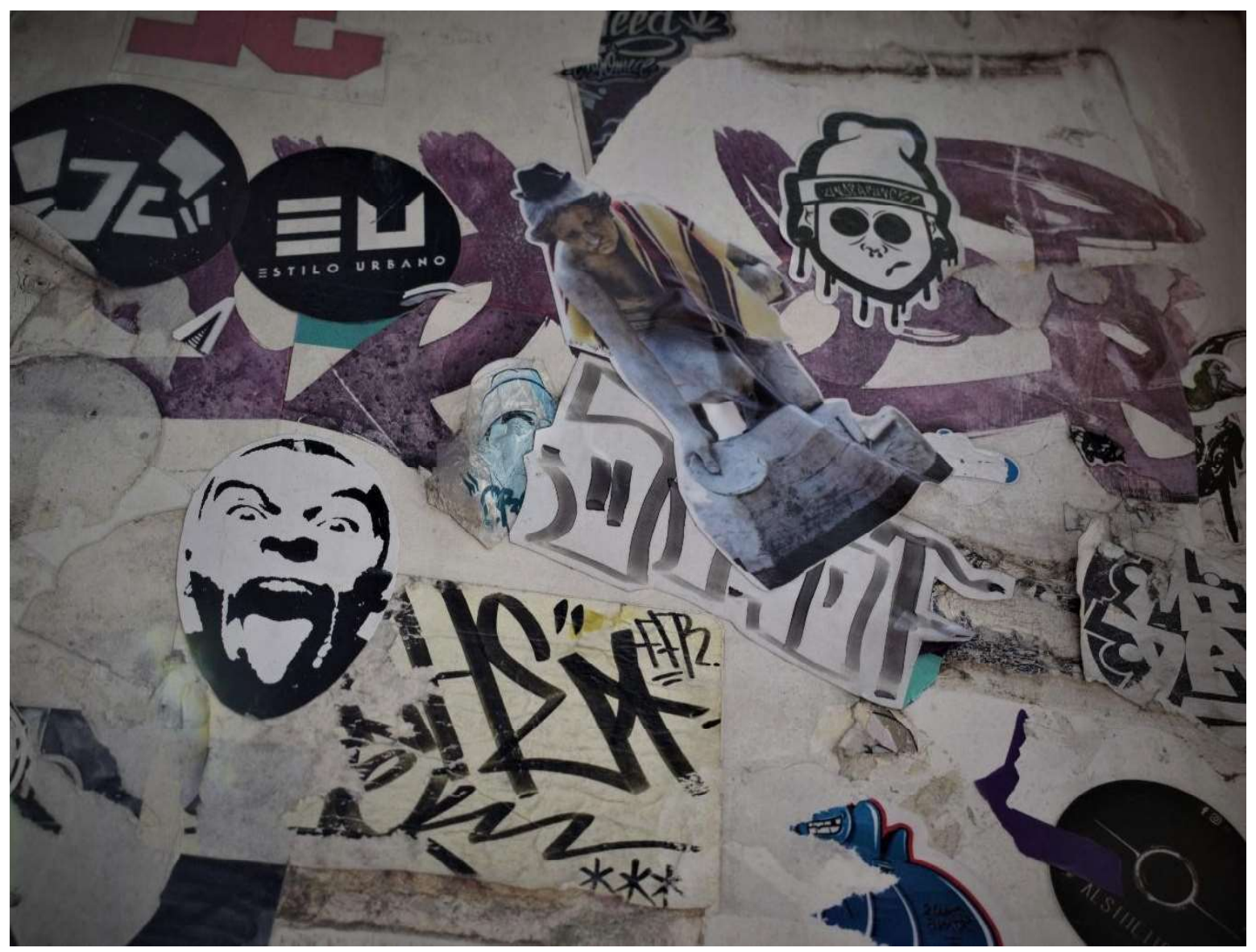

Imagen No 3. Bombing Mnemósine. Calle 19 con carrera 4ta, Bogotá. Fotografía propia.

Es en esta medida donde la representación simbólica adquiere su carácter palimpséstico como gesto comunicativo. En palabras de Montoya:

"Superficie atiborrada de inscripción, auténtico espacio de una escritura polivalente, la ciudad va construyendo un inmenso territorio palimpséstico a medida que va asignando con sus huellas, sus marcas y sus registros los espacios de su entorno, los cuerpos sociales en los cuales se materializa los lugares de morada de sus habitantes. Al mismo tiempo que configura ese juego intrincado de identidades y de diferencias, de relaciones y de contradicciones en los cuales se reconocen sus habitantes. Sus espacios y lugares signan multiplicidad de referencias, reinscribiendo, la mayoría de las veces, sobre las huellas de su propio devenir, las historias de su presente"24

24 José Montoya, "Capítulo 1: entre huellas e íconos. Los palimpsestos estéticos citadinos", en: Pensamiento visual contemporáneo, ed., Margarita Monsalve, Cátedra de sede Marta Traba. (Bogotá, Universidad Nacional de Colombia, 2015), 38. 
Así las cosas, estas pegatinas que asisten a la batalla por la apropiación del espacio público en Bogotá también permiten construir una nueva perspectiva de la Historia desde las intersensibilidades que dialogan con la circulación de la imagen digna de amplios significados, transformando la Historia en paralelo a la variabilidad del espacio y, en consecuencia, de los contextos que le otorgan legitimidad.

\section{Conclusiones y posibilidades}

Una Historia con las artes a partir de la producción visual consiente dos aspectos importantes a saber: la presencia de lo visual en términos de memoria gráfica como arraigo al territorio, pero también como generadora de divergencias que transitan en diferentes formatos que, en términos de palimpsestos urbanos, dejan rastros efímeros de nuevas formas de pensar la Historia y el espacio público en tanto se movilizan por distintos escenarios mientras sepultan simultáneamente la función clásica de las imágenes en la Historia.

Un claro ejemplo de ello es la incidencia crítico-política que ha tenido Puro Veneno en las principales ciudades de Colombia a partir de la activación de, no sólo otros mecanismos de protesta social, sino del tránsito de las producciones visuales en el espacio público percibidas como objetos contemplativos a microhistorias contestatarias que sobrepasan las fronteras de cooptación institucional cuyos intereses contribuyen a establecer las dicotomías entre aquello que resulta "vandálico" y aquello que no lo es. Ello permite considerar que "una cultura que conceda preminencia a la forma narrativa es indudable que ya no tiene necesidad de procedimientos especiales para autorizar sus relatos" ${ }^{25}$ pues, ante la circulación continua de formatos y formas de relatar una Historia distante del estatismo como los casos en mención, destacan las imposibilidades de narrar una Historia formal y unitaria.

Es por esto y más que me atreveré a concluir estas aproximaciones a una Historia crítica con una cierta insinuación a abordar las prácticas sensibles como instancias discursivas para construir posibilidades de una Historia con las artes que, aunque no desestime las interlocuciones entre relatos distinguidos por su primacía, abone un terreno fértil para concebir las manifestaciones estéticas como modos de resignificar la Historia más que contribuir de manera insulsa a instrumentalizarla.

\section{Bibliografía}

Benjamin, Walter. La obra de arte en la época de su reproductibilidad técnica. México: Editorial Ítaca, 2003.

25 Jean François Lyotard, "Capítulo 6: pragmática del saber narrativo", en: La condición posmoderna. (Madrid: Ediciones Cátedra, 1994), 49. 
.Tesis sobre la historia y otros fragmentos. Bogotá: Ediciones Desde Abajo, 2010 .

Burke, Peter. "Obertura: la nueva historia, su pasado y su futuro". En Formas de hacer historia, editado por Peter Burke [et al.]. Madrid: Alianza editorial, 2003.

Carranza, María. De Boyacá en los campos. (s.f.). Consultado el día 8 de agosto de 2019. https://www.lacoladerata.co/cultura/versos/maria-mercedes-carranza-poemas/

Erll, Astrid. Memoria colectiva y culturas del recuerdo: estudio introductorio. Bogotá: Universidad de los Andes, 2012.

Eskorbuto. Nadie es inocente. (s.f.). Consultado el día 8 de agosto de 2019. https:// www.letras.com/eskorbuto/848759/

Gaviria, Alejandra. Las calles también hablan. Memoria y espacio público. Bogotá: Centro de Memoria, Paz y Reconciliación, 2015.

Jelin, Elizabeth. ¿De qué hablamos cuando hablamos de memorias? En, Jelin, E. Los trabajos de la memoria. (2001). Consultado el día 8 de agosto de 2019. https:// laasociacion.files.wordpress.com/2015/11/memoria-jelc3adn-1.pdf

Lyotard, Jean Francois. "Capítulo 6: pragmática del saber narrativo”. En La condición posmoderna. Madrid: Ediciones Cátedra, 1994.

Montoya, José. "Capítulo 1: entre huellas e íconos. Los palimpsestos estéticos citadinos". En Pensamiento visual contemporáneo, editado por Margarita Monsalve, Cátedra de sede Marta Traba. Bogotá: Universidad Nacional de Colombia, 2015.

Nietzsche, Friedrich. Segunda consideración intempestiva. Sobre la utilidad y los inconvenientes de la historia para la vida. Buenos Aires: Libros del Zorzal, 2006.

Puro Veneno. Antología de una revuelta gráfica. 42-43. Bogotá: La Valija de Fuego, 2019.

Quintero, Juan. “QQué tan fuerte hay que gritar?” En, Puro Veneno. Antología de una revuelta gráfica. 42-43. Bogotá: La Valija de Fuego, 2019. 
Sharpe, Jim. "Capítulo 2: historia desde abajo". En Formas de hacer historia, editado por Peter Burke [et al.]. Madrid: Alianza editorial, 2003.

Suárez, Sylvia y Roca, José. Transpolítico. Arte en Colombia 1992 - 2012. Bogotá: Lunwerg Editores, 2012. 